\title{
The INGV real time strong motion data sharing during the 2016 Amatrice (cen- tral Italy) seismic sequence
}

\author{
MARCO MASSA*, EZIO D'Alema*, Claudia MASCANDOlA*, SARA LOVATI*, DAVIDE \\ SCAFIDI **, GIANLORENZO FRANCESCHINA*, ANTONIO GOMEZ*, SIMONA CARANNANTE*, \\ DAVIDE PICCARREDA*, SANTI MiRENNA*, PAOLO AUGLIERA*
}

*Istituto Nazionale di Geofisica e Vulcanologia, Milano, via Alfonso Corti 12, 20133, Milano, Italy

** Università degli Studi di Genova, DISTAV, viale Benedetto XV, 5, 16132, Genova, Italy

marco.massa@ingv.it

\begin{abstract}
During the August-September 2016 Amatrice, Mw 6.0, seismic sequence, the real time INGV strong motion data sharing was assured by the INGV Strong Motion database (ISMD). Starting on August 24th, the main task of the web portal was to archive, process and distribute the strong-motion waveforms recorded by the permanent and temporary INGV accelerometric stations for the earthquakes with magnitude $\geq 3.0$, occurring in the Amatrice area and surroundings. At present (i.e. September 30th, 2016), ISMD freely provides more than 21.000 strong motion waveforms to all users. In particular, about 2.200 strong motion waveforms were recorded by the temporary network installed for the earthquake sequence monitoring in the epicentral area by SISMIKO and EMERSITO working groups. In addition, for each permanent and temporary recording site, the web portal provides a comprehensive description of the necessary information to properly use the strong motion data.
\end{abstract}

\section{INTRODUCTION}

$\mathrm{O}$ n August $24^{\text {th }}, 2016$, at 01:36:32 UTC, a Mw 6.0 (http://cnt.rm.ingv.it/) earthquake struck a wide area of the Central Apennines (Italy), located between the towns of Norcia and Amatrice (Figure 1, top panel). The mainshock resulted in diffuse building collapses and about 290 casualties.

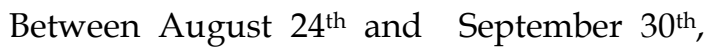
the seismic sequence produced thousands of earthquakes, 16 of which with magnitude $\geq$ 4.0 (http://cnt.rm.ingv.it/). The strongest aftershock (Mw 5.4) was recorded on 201608-24 at 02:33:29 UTC.

During important seismic sequence the scientific research in the seismological and engineering fields requires rapid acquisition of strong motion data for several purposes, such as the evaluation of the available ground motion prediction equations (GMPEs) and the verification of ground 
shaking scenarios and probabilistic seismic hazard maps. Nowadays the great demand of strong motion data is satisfied by several strong motion databases, each one with different aim and philosophy. At Italian scale, data and metadata are freely available both from the INGV Strong Motion database (ISMD, http://ismd.mi.ingv.it) and the ITalian ACcelerometric Archieve (ITACA, http://itaca.mi.ingv.it). While ISMD publishes the real time strong motion data recorded by the permanent and temporary stations of the National Seismic Network (RSN, http://cnt.rm.ingv.it/instruments/network /IV), ITACA provides once a year the manually post processed data recorded by the Italian Accelerometric Network (RAN, http://www.protezionecivile.gov.it/jcms/it /ran.wp), even if, since 2014 also a set of INGV stations are included in the database. At European scale, the related counterparts are the Rapid Raw Strong Motion database (RRSM, www.orfeus-eu.org/rrsm/) and the Engineering Strong Motion database, http://esm.mi.ingv.it/), respectively.

During the Amatrice seismic sequence (i.e. from August 24 to September 30, 2016) ISMD gave freely available strong motion data (and related metadata) in Sac raw and Ascii corrected formats of 118 events with $3.0 \leq \mathrm{M}$ $\leq 6.0$. A subset of 71 events (not including the temporary stations for emergency) with $M \geq 3.5$ were also available at RRSM web site, where data are downloadable in MiniSeed raw format by consulting the European Integrated Data Archive (EIDA, www.orfeuseu.org/eida). Moreover, a manual revision of the 16 events with $\mathrm{Mw} \geq 4.0$ occurred during the sequence was published some days after the earthquakes occurrence on ESM web site.
This paper describes in detail, the ISMD real time strong motion data set made available to the community through the website http://ismd.mi.ingv.it since the early morning of the $24^{\text {th }}$ August 2016.

\section{ISMD 2.0: DATABASE AND WEBSITE}

ISMD 2.0 is based on PostgreSQL (www.postgresql.org), an advanced and reliable open source object-relational database management system. The earthquakes parametric data and the ground motion parameters, as resulting from the automatic analyses, are stored in the PostgreSQL database in order to have a complete integrated archive, easily accessible and ready for use. Waveform data and images are linked to the database and stored as separate files, organized by year and event-id, in order to ensure a direct data access for different purposes. Data and metadata are freely available after the user registration. Through the unique event-id, each earthquake is directly linked to the related web-pages of Shakemaps (http://shakemap.rm.ingv.it/) and Time Domain Moment Tensor (http://cnt.rm.ingv.it/tdmt/) databases. Both permanent and temporary seismic stations are characterized in terms of instrumentation and features of the recording site (i.e. geology, morphology, passive seismic analyzes and seismic code classifications). In case of earthquakes with magnitude $\geq 4.0$, ISMD 2.0 provides a revised version of the published data in order to avoid false ground motion parameters calculated on recordings with 
low signal to noise ratio or biased by spurious spikes, malfunctioning in data transmission or event superimposition. The revision is operated by an expert seismologist in the first 48 hours after the event origin time (see MAN in the last column of the earthquake-list web page).

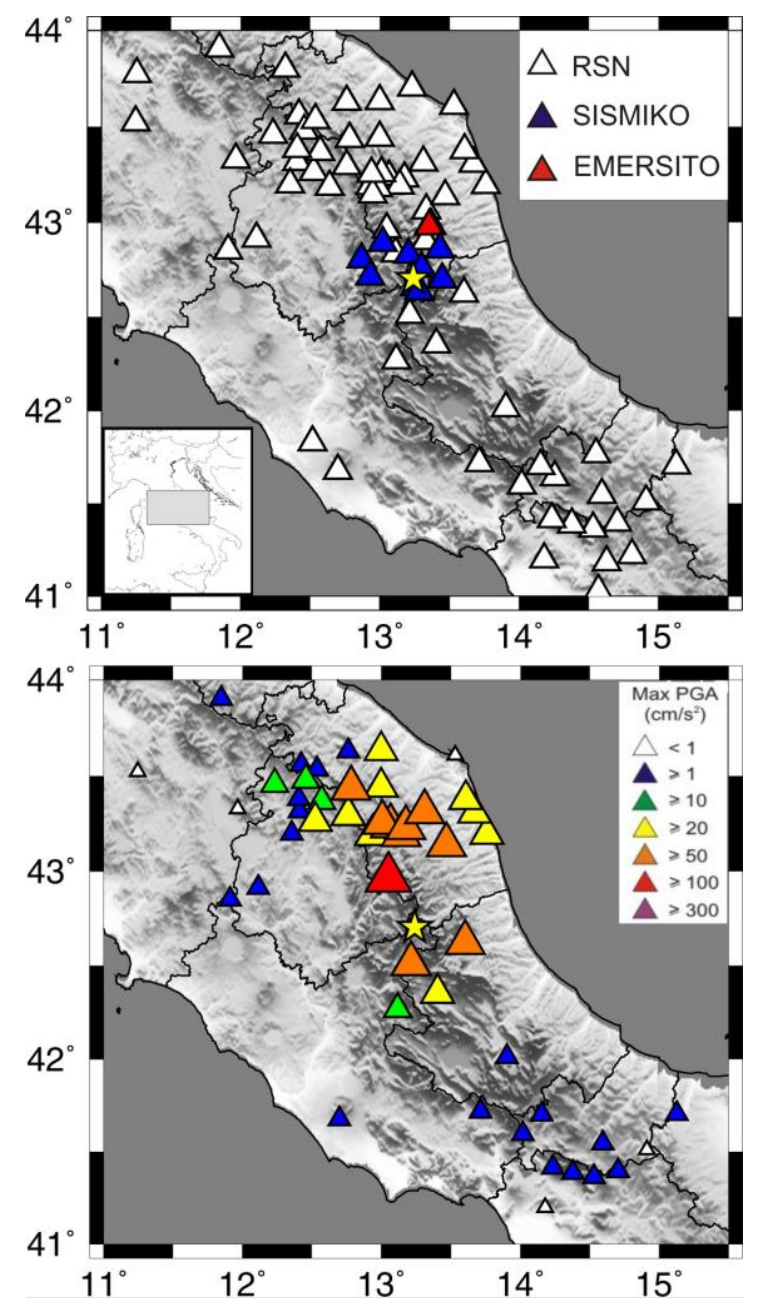

Figure 1. Top: INGV strong motion stations analyzed during the 2016 Amatrice sequence. Bottom: PGA map for the $24^{\text {th }}$ August, Mw 6.0, mainshock. The yellow star indicates the epicenter of the mainshock.
The website was written in HTML 5 (https://www.w3.org/TR/html5/) to meet the most recent validation standards of the W3C (World Wide Web Consortium) and in PHP (http://www.php.net/). All published materials are licensed under a Creative Commons license.

\section{AMATRICE 2016 DATA SET}

On August 24th 2016, at 05:57:52 (UTC) ISMD published the first automatic report of the Mw 6.0 mainshock. In this case the delay of about 4 hours with respect to the event origin time (i.e. 01:36:32 UTC) depended on the time required to revise both the event location (operated by INGV-CNT) and the ground motion parameters calculated from the ISMD automatic data processing. Moreover, due to the high density of stations installed in the epicentral area, the automatic report required almost 1 hour to make online waveforms available, together with the related metadata and all the automatic analyses (Massa et al., 2014). In order to publish data as fast as possible, only the accelerometric stations with epicentral distance less than $200 \mathrm{Km}$ were considered in the automatic analyses.

For the mainshock, ISMD contains a total of 126 accelerometric waveforms related to 42 permanent RSN strong motion stations (Figure 1, top panel). Further 7 stations were discarded after the manual revision. The two stations closest to the mainshock (Figure 1, bottom panel) were RM33 (Montereale) and TERO (Teramo), located $22 \mathrm{~km}$ South and 31 $\mathrm{km}$ East of the epicenter, respectively. RM33 and TERO recorded maximum PGAs of 91 
and $84 \mathrm{~cm} / \mathrm{s}^{2}$, respectively, both on the N-S horizontal components. However the highest value of acceleration, $241 \mathrm{~cm} / \mathrm{s}^{2}$, was recorded at FEMA (Monte Fema), located 32 km NW of the epicenter (Figure 2).

The total dataset collected between August $24^{\text {th }}$ and September $30^{\text {th }}, 2016$, consists of 21.000 strong motion waveforms recorded by the real-time permanent and temporary INGV accelerometric stations. Data are shown in Figure 3, considering the soil categories as indicated in Eurocode8 (CEN, 2003). The data set includes 433 waveforms with PGA from $10 \mathrm{~cm} / \mathrm{s}^{2}$ to $50 \mathrm{~cm} / \mathrm{s}^{2}, 64$ waveforms with PGA from $50 \mathrm{~cm} / \mathrm{s}^{2}$ to 100 $\mathrm{cm} / \mathrm{s}^{2}$ and 8 waveforms with PGA $>100$ $\mathrm{cm} / \mathrm{s}^{2}$ (Figure 3, top panel). Concerning the PGV, 152 waveforms are characterized by PGV ranging from $1 \mathrm{~cm} / \mathrm{s}$ to $5 \mathrm{~cm} / \mathrm{s}, 19$ with PGV ranging from $5 \mathrm{~cm} / \mathrm{s}$ to $10 \mathrm{~cm} / \mathrm{s}$ and 1 with PGV $>10 \mathrm{~cm} / \mathrm{s}(14.5 \mathrm{~cm} / \mathrm{s}$ recorded at FEMA during the mainshock).

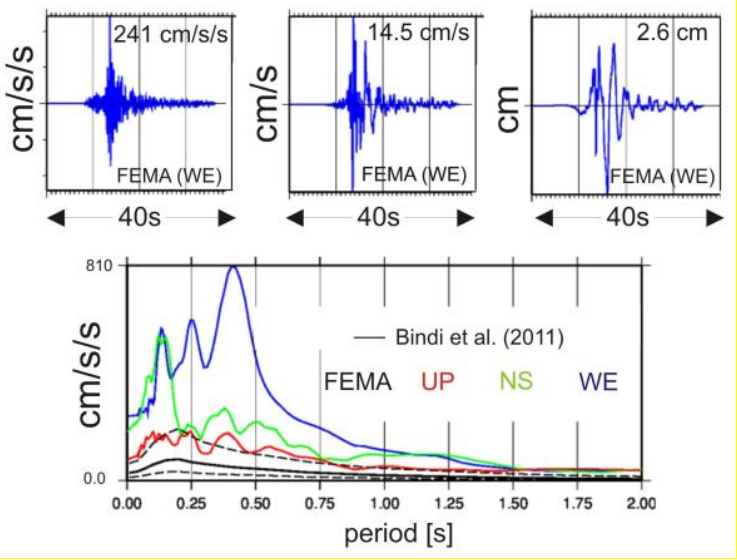

Figure 2. Top: Acceleration (left), velocity (center) and displacement (right) recorded at FEMA during the Mw 6.0 event. Bottom: recorded and predicted (Bindi et al., 2011) elastic acceleration response spectra.
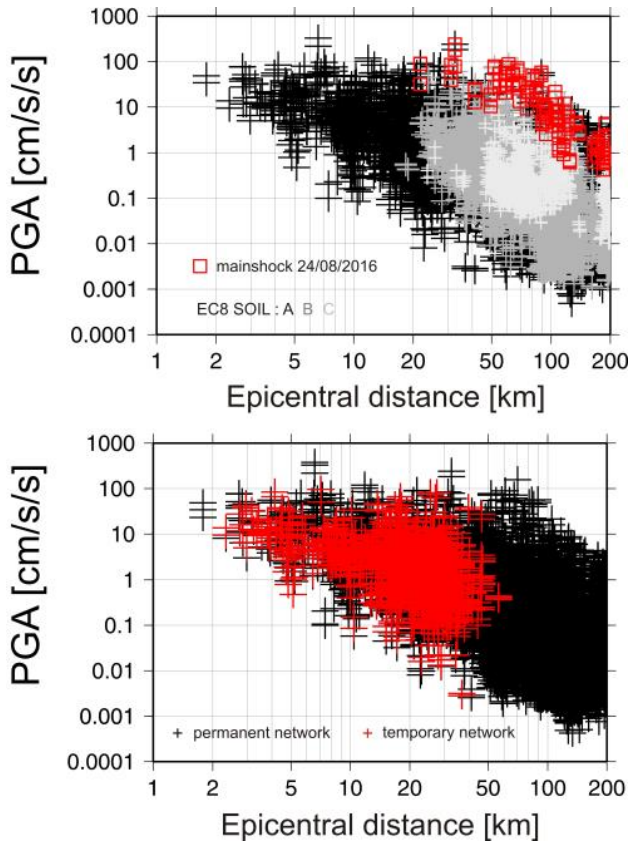

Figure 3. Top: PGA recorded from INGV strong motion stations during the sequence. Data are shown for different EC8 soil categories. In red the 24th August mainshock. Bottom: data recorded by the permanent (black) and the temporary (red) INGV stations.

In particular, the installation of the temporary seismic network allowed us to collect a high quality near field strong motion data set including $\sim 2,200$ recordings with the epicentral distance $<30 \mathrm{~km}$ (Figure 3 , bottom panel). Between the temporary stations, the highest PGA $\left(96 \mathrm{~cm} / \mathrm{s}^{2}\right)$ was recorded by T1201 during the Mw 4.8 event (2016/08/26 04:28:25 UTC). In particular, ISMD analyzed in quasi real time $\sim 1,600$ strong motion data recorded by SISMIKO (Moretti et al., 2016) and $\sim 600$ recorded at Amandola by EMERSITO (Cultrera et al., 2016). All the strong motion data analyzed during the sequence are downloadable both in raw SAC and in processed ASCII formats. 


\section{DISCUSSION}

Figure 4 shows the PGA and PGV values recorded during the main Italian seismic sequences that occurred in the past 10 years (L'Aquila, Mw 6.1; Mirandola Mw 5.8; Lunigiana $\mathrm{Mw}$ 5.1; Amatrice $\mathrm{Mw}$ 6.0; http://cnt.rm.ingv.it/tdmt/). The apparent higher values of PGA and PGV observed during the L'Aquila (Ameri et al., 2009) and the Mirandola sequences (Luzi et al., 2013) are due to the presence of strong motion stations with epicentral distance $<10 \mathrm{~km}$. Indeed, if we consider a range of distances from 20 to $70 \mathrm{~km}$, it is possible to verify that ground accelerations and velocities recorded during the Amatrice and L'Aquila sequences are fully comparable.

The PGA distribution observed during the Amatrice mainshock (Figure 1, bottom panel) shows the highest values of ground motion in N-NE direction. This distribution is also recognizable in the seven aftershocks with $\mathrm{Mw} \geq 4.5$, and can be due to the rupture directivity involving the normal fault (Spagnuolo et al., 2016) and/or to the seismic waves propagation effects. The latter property was already observed during the 2009 L'Aquila sequence by Ameri et al. (2009).

The collection of strong motion data published on ISMD after the manual revision allows to evaluate the GMPE currently available for Italy (Bindi et al., 2011). Concerning the $24^{\text {th }}$ August mainshock, Figure 5 shows that the current models (at least in terms of PGA and PGV) tend to slight underestimate the near source and near field data, while at distances $>50 \mathrm{~km}$ it is possible to note as the recorded data decay faster with respect to the current predictions, independently from the EC8 sites classification.
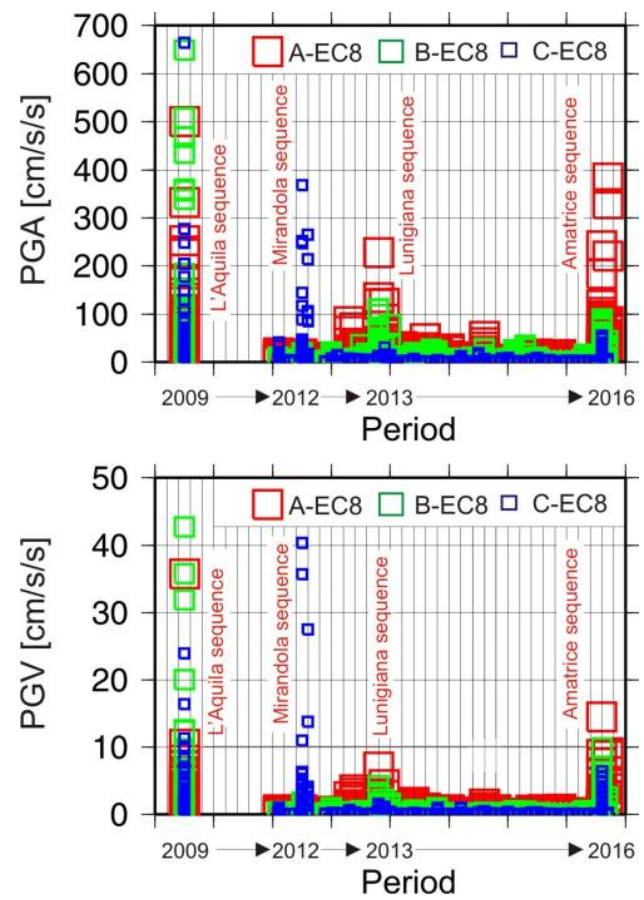

Figure 4. PGA (top) and PGV (bottom) recorded from INGV strong motion stations during the main Italian sequences occurred in the last 10 years.

The same comparison were made considering the 16 events with magnitude $\geq$ 4.0 ( 3.200 accelerograms) recorded in the analyzed period. The results are presented in figure 6 in terms of bias, defined as the residual between observed and predicted ground motion, evaluated using the maximum likelihood formalism proposed by Spudich et al. (1999). Negative and positive bias indicate that the predicted model overestimates and underestimates the recorded ground motion, respectively. Specifically, the slope of the straight line that 
best fits the residuals as a function of $\log$ distance (Fig. 6, left) or magnitude (Fig. 6, right) is indicative of the dependence of the residuals on the independent variable considered.
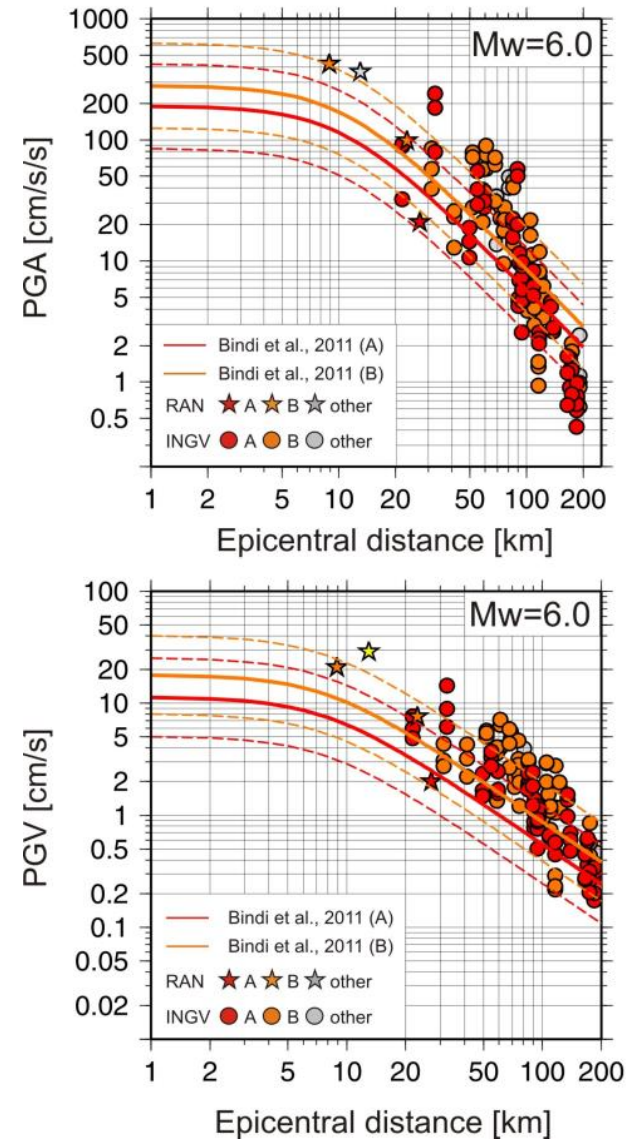

Figure 5. PGA (top) and PGV (bottom) for the $24^{\text {th }}$ August mainshock (Mw 6.0) compared to the Bindi et al. (2011) Italian GMPEs. Stars indicate data at distance $<30 \mathrm{~km}$ recorded by RAN. Colors indicate different EC8 (CEN, 2003) site categories.

In general, both PGA and PGV show a good agreement between observed and predicted data. In both cases (Fig. 6), the bias indicates a slight overestimation of the predictions. However, Figure 6 highlights a clear increasing overestimation of the predictions with increasing distance (more evident for PGA, top left panel) and an increasing underestimation of the models with increasing magnitude (more evident for PGV, bottom right panel). In particular, a reason for the PGA overestimation at large distance might be the contribution of the anelastic attenuation. In general, it is worth mentioning that the preferential propagation pattern in North direction (Fig. 1, bottom) combined to the not uniform distribution of stations around the epicenters might slightly influence the final results.

Even if this preliminary consideration has to be carefully corroborate with further tests, the results might however represent a warning on the necessity to revise the current models for the central Italian Apennines in order to assure a more accurate evaluation of the regional seismic hazard.

\section{REFERENCES}

[Ameri, 2009] Ameri G., Massa M., Bindi D., D'AlemaE., Gorini A., Luzi L., Marzorati M., Pacor F., Paolucci R., Puglia R. and Smerzini C. (2009). The 6 April 2009, Mw 6.3, L'Aquila (Central Italy) earthquake: strong-motion observations, Seism. Res. Lett., 80, n 6, 951966.

[Bindi, 2011] Bindi, D., Pacor, F., Luzi, L., Puglia, R., Massa, M., Ameri, G. and R. Paolucci (2011). Ground Motion Prediction Equations Derived from the Italian Strong Motion Data Base, Bull. Earth. Eng. 9, n. 6, 1899-1920.

[CEN, 2003] CEN (2003). prEN 1998-1- Eurocode 8: design of structures for earthquake resistance. P1: General rules, seismic actions 
and rules for buildings. Draft 6, Doc CEN/TC250/SC8/N335, Jan 2003, Brussels. [Cultrera, 2016] Cultrera G., D'Alema E. and Emersito working group (2016). Emersito Task Force activities after the Mw 6.0 Amatrice Earthquake (August 24th, 2016, Central Italy). Ann. Geoph., this issue.

[Luzi, 2013] Luzi L., Pacor F., Ameri G., Puglia R., Burrato P., Massa M., Augliera P., Castro R., Franceschina G., Lovati S. (2013). Overview on the strong motion data recorded during the May-June 2012 Emilia seismic sequence, Seism. Res. Lett., vol. 84, n. 4.

[Massa, 2014] Massa M., Lovati S., Franceschina G., D'Alema E., Marzorati S., Mazza S., Cattaneo M., Selvaggi G., Amato A., Michelini A., Augliera P. (2014). ISMD, a web portal for the real time processing and dissemination of INGV strong-motion data, Seism. Res. Lett., vol. 85, n. 4, 727-734.

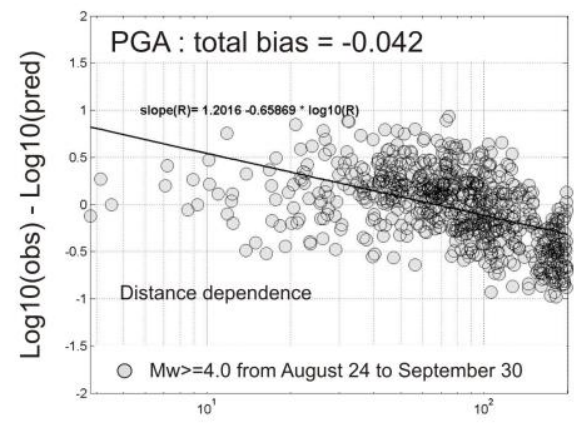

Epicentral distance $[\mathrm{km}]$

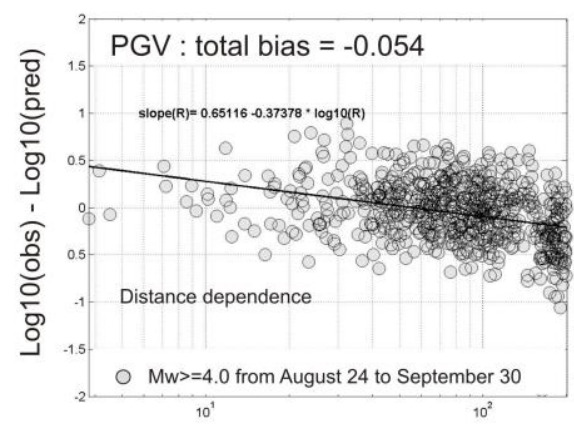

Epicentral distance $[\mathrm{km}]$
[Moretti, 2016] Moretti M., Pondrelli S., Margheriti L. and Sismiko working group (2016). Sismiko: emergency network deployment and data sharing in the 2016 Amatrice seismic sequence. Ann. Geoph., this issue.

[Spagnuolo, 2016] Spagnuolo E., Cirella A., Akinci A. (2016). Investigating the effective ness of rupture directivity during the August 24, $2016 \mathrm{Mw} 6.0$ central Italy earthquake. Ann. Geoph., this issue.

[Spudich, 1999]. Spudich, P., W. B. Joyner, A. G. Lindh, D. M. Boore, B. M. Margaris, and J. B. Fletcher (1999). SEA99: a revised ground motion prediction relation for use in extensional tectonic regimes, Bull. Seism. Soc. Am., 89, 1156-1170.

Figure 6. Residual analysis of PGA (top) and PGV (bottom), for 16 events with $M w \geq 4.0$ recorded in the Amatrice area from August 24 to September 30, 2016 with respect to the Bindi et al. (2011) GMPEs. Left and right panels indicate the dependence of the residuals on epicentral distance and magnitude respectively.

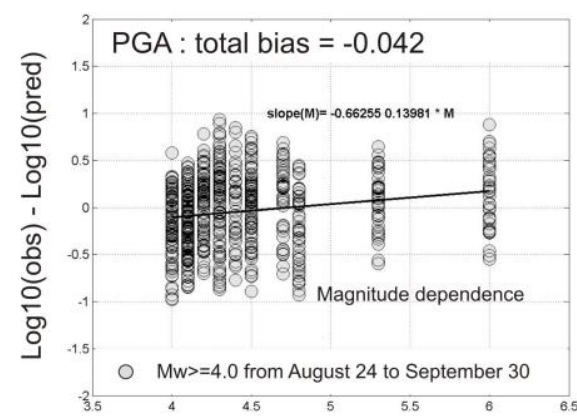

$\mathrm{Mw}$

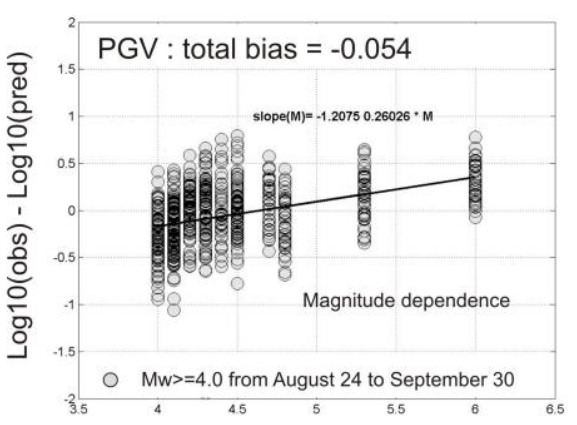

Mw 